\title{
Persistent Neuroblastic Cells
}

National Cancer Institute

\section{Source}

National Cancer Institute. Persistent Neuroblastic Cells. NCI Thesaurus. Code C129904.

A morphologic finding indicating the continuing presence of neuroblastic cells in a set of tissue samples collected over time. 